\title{
Tejedoras de futuro: La participación política de las mujeres mapuce en el conflicto territorial de Neuquén (1995-2015)
}

\author{
Weavers of future: Political participation of Mapuce women in the territorial \\ conflict of Neuquén (1995-2015)
}

\section{Suyai Malen García Gualda}

\section{OpenEdition}

\section{Journals}

Electronic version

URL: http://journals.openedition.org/corpusarchivos/2271

DOI: $10.4000 /$ corpusarchivos.2271

ISSN: $1853-8037$

Publisher

Diego Escolar

\section{Electronic reference}

Suyai Malen García Gualda, «Tejedoras de futuro: La participación política de las mujeres mapuce en el conflicto territorial de Neuquén (1995-2015) », Corpus [En línea], Vol. 8, No 1 | 2018, Publicado el 29 junio 2018, consultado el 19 abril 2019. URL : http://journals.openedition.org/corpusarchivos/2271 ; DOI : 10.4000/corpusarchivos.2271

This text was automatically generated on 19 April 2019.

Licencia Creative Commons: Atribución-NoComercial 2.5 Argentina (CC BY-NC 2.5 AR) 


\section{Tejedoras de futuro: La participación política de las mujeres mapuce en el conflicto territorial de Neuquén (1995-2015)}

Weavers of future: Political participation of Mapuce women in the territorial conflict of Neuquén (1995-2015)

Suyai Malen García Gualda

\section{EDITOR'S NOTE}

TESISTA: Suyai Malen García Gualda DIRECTOR: Dr. Fernando A. Lizárraga CO-DIRECTORA: Dra. Gloria M. Hintze GRADO: Doctorado en Ciencias Sociales INSTITUCION: Universidad Nacional de Cuyo Facultad de Ciencias Políticas y Sociales FECHA DE DEFENSA: 2017

CIUDAD: Mendoza

\section{NOTES}

1. En la presente tesis se utiliza el término "mapuce" según el grafemario Ragileo. 


\section{ABSTRACTS}

En la década de 1990 América Latina fue escenario del surgimiento y (re)aparición de diversos movimientos indígenas que lograron presentarse claramente como nuevos actores políticos. Este importante proceso ha puesto en evidencia la realidad que atraviesan las mujeres indígenas como consecuencia de la opresión que padecen producto de la intersección entre género, etnia y clase. Las mujeres mapuce ${ }^{1}$ no han sido la excepción, por ello en la presente tesis nos adentramos en el análisis de su realidad, demandas y luchas a fin de analizar su participación política en diferentes momentos de conflicto en la provincia norpatagónica de Neuquén; y el impacto que dicha participación ha tenido en el orden social y de género(s) mapuce. A tal fin nos proponemos dar cuenta sobre el proceso de transformación sociocomunitaria que tuvo lugar en el seno de las comunidades y organizaciones (supra o macro comunitarias) originarias, a partir de la participación de las mujeres en diversos espacios de negociación y resistencia. Por ello, buscamos conocer las estrategias que las mujeres han emprendido en contextos violentos de acumulación por desposesión y despojo. Nuestra propuesta de análisis busca advertir las continuidades históricas que se mantienen presentes desde la mal llamada Conquista del Desierto en el siglo XIX hasta nuestros días, sin perder de vista la larga memoria extractivista que caracteriza a estos territorios sureños. Por lo dicho, comenzamos con una descripción general e histórica del Pueblo/Nación Mapuce en Pwelmapu, especialmente en Neuquén. Luego, nos detenemos en el contexto que dio origen al conflicto más emblemático de las últimas décadas: Pulmarí. Nuestra tesis sostiene que a partir de entonces y en lucha contra la opresión que padecen producto de los intercruces entre género, etnia y clase- las mapuce se han convertido en actoras políticas estratégicas en la provincia de Neuquén. Por esto, a partir de allí nos proponemos pensar y abordar la participación de las mujeres mapuce en los conflictos contemporáneos, en zonas turísticas de montaña y en territorios azotados por la explotación de yacimientos no convencionales de gas y petróleo. Finalmente, es preciso indicar que a lo largo de esta investigación aplicamos una estrategia metodológica cualitativa y hacemos uso del método etnográfico. A nuestro juicio, conocer estas otras realidades y luchas, desde la ciencia política y con aportes de los estudios de género, supone una interesante y necesaria contribución -teóricaa nuestro campo disciplinar. 